Research Article

\title{
Evaluation of Vegetable Circulation Efficiency and Analysis of Influencing Factors in Henan Province
}

\author{
Xueqiang Guo $\mathbb{D}^{1}$ and Bingjun $\mathrm{Li} \mathbb{D}^{2}$ \\ ${ }^{1}$ College of Mechanical and Electrical Engineering, Henan Agricultural University, Zhengzhou 450002, China \\ ${ }^{2}$ College of Information and Management Science, Henan Agricultural University, Zhengzhou 450046, China
}

Correspondence should be addressed to Bingjun Li; zzlbjun@163.com

Received 15 July 2021; Revised 10 September 2021; Accepted 23 September 2021; Published 7 October 2021

Academic Editor: Shaojian Qu

Copyright (c) 2021 Xueqiang Guo and Bingjun Li. This is an open access article distributed under the Creative Commons Attribution License, which permits unrestricted use, distribution, and reproduction in any medium, provided the original work is properly cited.

\begin{abstract}
In order to explore the deep-seated reasons affecting the development of vegetable circulation in Henan Province, combined with the panel data of Henan Province from 2014 to 2019, this paper first makes a static analysis on the vegetable circulation efficiency in Henan Province by using DEA method. Second, the Malmquist method is used to establish the total factor productivity evaluation model of vegetable circulation in Henan Province, and the dynamic analysis is carried out. The analysis results show that the main problem in the development of vegetable circulation in Henan Province is the low level of management and technology. Then, $\mathrm{GM}(1, \mathrm{~N})$ model is established to further analyze the specific factors affecting the vegetable circulation efficiency in Henan Province. Finally, some reasonable suggestions are put forward for the development of vegetable circulation in Henan Province.
\end{abstract}

\section{Introduction}

Vegetable circulation plays a very important role in commodity circulation, which is not only related to the vital interests of farmers but also related to the development of China's agricultural economy. Vegetable circulation is the link between production and sales, also an important guarantee to realize the value of vegetables and increase farmers' income. In economics, efficiency usually refers to the ratio of output to input in economic activities. Vegetable circulation efficiency refers to the ratio of output to input in the process of vegetable circulation, which reflects the effectiveness of resource allocation. In recent years, the scale of vegetable production in Henan Province has expanded year by year. In order to ensure the increase of farmers' production and income, it is urgent to improve the efficiency of vegetable circulation and promote the high-quality development of vegetable circulation. Therefore, the research on vegetable circulation efficiency has important practical significance.
The research of vegetable circulation efficiency not only enriches the theoretical system of vegetable circulation research and expands the space and vision of vegetable circulation research but also reduces the cost and loss of vegetable circulation, which is conducive to improving the income level of farmers. Scholars have studied the current situation and problems of vegetable circulation from different perspectives. Zhang [1] believes that the main problems existing in the circulation of vegetable market in China are the lag of infrastructure construction of vegetable market, the imperfection of vegetable market system and market mechanism, and the low degree of organization of vegetable circulation subject. Yuan and Xin [2] believe that government departments should formulate relevant flexible policies, stabilize vegetable production and sales prices, monitor the demand change information of residents in real time, and guide farmers to plant differently. Wang and Chen [3] believe that the main problems in China's vegetable circulation are low degree of organization, many circulation links, and low degree of standardization. $\mathrm{Wu}$ and $\mathrm{Mu}$ [4] used the spatial dynamic panel model to analyze the spatial- 
temporal correlation and influencing factors of regional circulation of vegetables. Kuang et al. [5] believe that cultivating and strengthening the main body of production and dredging the links of production and marketing are powerful means to promote the quality and efficiency of vegetable industry. Shang and Huang [6] found that the traditional vegetable circulation mode occupies the main position, and the wholesale market occupies the core position in the vegetable circulation. Shen et al. [7] proposed strengthening the release of information early warning, guiding farmers to grow rationally, innovating and improving the circulation mode, and promoting the docking of vegetable production and marketing. Shen and $\mathrm{Mu}[8]$ found that Beijing vegetable market operation has obvious seasonality.

On the analysis and evaluation of vegetable circulation efficiency, scholars have studied it from various angles and achieved fruitful results. Zhou and $\mathrm{Lu}$ [9] analyzed the efficiency of different circulation channels of fresh vegetables in Nanjing. Su [10] thought that the circulation efficiency of agricultural products mainly depends on the wholesale link and proposed that the construction of agricultural products wholesale market should be strengthened. $\mathrm{He}$ and $\mathrm{Wu}$ [11] proposed measures to solve the problem of vegetable circulation efficiency in Wuhan from the perspective of economical circulation mode and administrative management. Guo [12] used data envelopment model to analyze and evaluate the channel efficiency with large supermarket chains as retail terminals. Jiang et al. [13] used analytic hierarchy process to calculate the weight of influencing factors in vegetable circulation and specifically analyzed the main influencing factors in the evaluation results. Jiang [14] constructed the circulation efficiency model of vegetables in Beijing suburbs and analyzed the decisive factors affecting the circulation efficiency. Zhang [15] conducted an empirical analysis on the circulation efficiency of vegetables and analyzed the deep-seated factors affecting the circulation efficiency of vegetables in China. Kim and An [16] used DEA method to study the technical efficiency of rice and vegetable farms. Shrestha et al. [17] used DEA method to evaluate the economic benefits of vegetable farms in Nepal. Shan [18] used data envelopment analysis method to analyze the circulation efficiency of real estate vegetables in Harbin from two aspects of input and output and put forward the optimization path of circulation efficiency of real estate vegetables from four aspects of circulation subject, circulation channel, circulation object, and circulation guarantee measures. Peng and Nan [19] used DEA-Malmquist method to analyze the differences of vegetable circulation efficiency between eastern China and Western China. Zheng [20] measured the circulation efficiency of fresh vegetables from the perspective of industrial chain and put forward the promotion strategy. $\mathrm{Li}$ and $\mathrm{Mu}$ [21] used the DEA Tobit twostage model to analyze the vegetable circulation efficiency of farmers in different channels under the wholesale market dominant mode and found that the age of the head of household, the number of years engaged in vegetable production, the distance between the agricultural product market and home, and whether to join the cooperative are the main factors affecting the vegetable circulation efficiency of farmers. Akamin et al. [22] used the stochastic frontier analysis method to estimate the technical efficiency of vegetable farmers and tested its influencing factors. Anik and Salam [23] estimated the driving factors and technical efficiency of okra and eggplant production. Ye [24] used DEA model to evaluate the efficiency of main circulation modes of leafy vegetables in Nanchang suburbs. Bournaris et al. [25] used DEA method to evaluate the production efficiency of greenhouse vegetables. Nedumaran et al. [26] constructed the fresh fruit and vegetable supply chain model and improved the efficiency of the fresh vegetable supply chain.

From the existing research results, domestic scholars mainly focus on theoretical research on the current situation and problems of vegetable circulation. On the analysis and evaluation of vegetable circulation efficiency, foreign scholars mainly focus on the efficiency research in the field of vegetable production, while domestic researches mostly focus on the efficiency research of leading vegetable wholesale market or core vegetable circulation enterprises and take the efficiency of leading vegetable wholesale market or core vegetable circulation enterprises as the evaluation standard of vegetable circulation efficiency in specific areas. It has the disadvantage of generalizing. Due to the lack of a perfect statistical index system in China's vegetable circulation industry, the relevant evaluation indexes have the characteristics of small samples, and even some evaluation indexes still have the problem of lack of data. Using traditional methods such as econometric regression to analyze and evaluate the efficiency of vegetable circulation may produce large deviation. In addition, the vegetable circulation system is a complex system, so it is difficult to find a suitable function model to analyze the circulation efficiency. The Malmquist index analysis method of data envelopment analysis (DEA) has the advantages of no need to set the function form in advance and being not affected by the number of samples and variable dimensions. It can effectively avoid the deviation of the preset model, realize the dynamic cross period measurement of efficiency, decompose the Malmquist index, and find the reasons for the change of the index. DEA-Malmquist method has become the mainstream method of efficiency evaluation. This paper uses DEA-Malmquist method to analyze and evaluate the efficiency of vegetable circulation in Henan Province from both static and dynamic perspectives.

On the research of influencing factors of vegetable circulation efficiency, the existing research results have reference significance for this paper, but little or no consideration has been given to the grey characteristics of influencing factors of vegetable circulation, such as partial information known, partial information unknown, and poor information. $\mathrm{GM}(1, \mathrm{~N})$ model is one of the grey models considering the influence of many factors, and it has been widely used and innovated. Ma and Liu [27] constructed a discrete $\mathrm{GM}(1, \mathrm{~N})$ model to analyze the basic law of oil production decline and the related influencing factors; Jiang et al. [28] put forward an improved $\mathrm{GM}(1, \mathrm{~N})$ model to forecast China's foreign direct investment; Xiong et al. [29] proposed $\operatorname{AWGM}(1, \mathrm{~N})$ model to predict housing demand; Yang and Li [30] used $\operatorname{GM}(1, N)$ model to predict the grain yield in 
China. This paper selects the grey $\mathrm{GM}(1, \mathrm{~N})$ model to analyze the influencing factors of vegetable circulation efficiency in Henan Province, explores the deep-seated reasons of influencing vegetable circulation efficiency, and puts forward suggestions for improvement, so as to promote the high-quality development of vegetable circulation industry in Henan Province.

\section{Research Methods}

At present, the analysis and evaluation methods of commodity circulation efficiency mainly include comprehensive evaluation method, frontier analysis method, and data envelopment analysis (DEA). The comprehensive evaluation method is subjective and has some human errors. The frontier analysis method is suitable for the efficiency evaluation of single output and needs large data samples, while the DEA method is suitable for the efficiency evaluation of multiple inputs and multiple outputs. Therefore, DEA method has become the mainstream way of efficiency evaluation.

2.1. DEA-BCC Model. CCR model and BCC model are widely used in DEA. Among them, the CCR model assumes that the return to scale of the decision-making unit is fixed, while the BCC model assumes that the return to scale of the decision-making unit is variable. Because there are many subjects to study and it is impossible to achieve the optimal production scale at the same time, and BCC model has the advantage of evaluating the relative technical effectiveness between different decision-making units, this paper uses BCC model for efficiency analysis and evaluation. Assuming that there are $n$ decision-making units, the BCC model can be expressed as

$$
\begin{aligned}
& \min \theta=V_{D}, \\
& \text { s.t. }\left\{\begin{array}{l}
\sum_{i=1}^{n} \lambda_{i} x_{i}+S^{-}=\theta x_{t} \\
\sum_{i=1}^{n} \lambda_{i} y_{i}-S^{+}=y_{t} \\
\sum_{i=1}^{n} \lambda_{i}=1, i=1,2, \ldots, n \\
\lambda_{i} \geq 0, S^{-}, S^{+} \geq 0
\end{array} .\right.
\end{aligned}
$$

In the above equation, $\theta$ is the comprehensive efficiency value of the $r$-th decision-making unit, which can be decomposed into technical efficiency and scale efficiency; $S^{-}$ and $S^{+}$are input slack variables and output slack variables, respectively; $\lambda_{i}$ is the weight of the $i$-th decision-making unit. When $V_{D}=1$ and $S^{-}=0$ and $S^{+}=0$, then the $r$-th decisionmaking unit is DEA efficient. When $V_{D} \neq 1$, it means that the $r$-th decision-making unit is DEA invalid.

2.2. Malmquist Index Model. In 1953, Malmquist, a Swedish economist and statistician, first proposed the Malmquist index model when he studied the consumption problem.
After combining with DEA theory, Malmquist index model has been widely used in the field of efficiency evaluation. Malmquist index focuses on observing the relative changes of multiperiod indexes, which is helpful to analyze the dynamic changes of efficiency. The basis of Malmquist index is distance function, which is the reciprocal of the comprehensive efficiency of BCC model. Malmquist index measures the dynamic change of TFP from $t$ period to $t+1$ period.

Suppose that the distance function $D^{t}\left(x_{r}^{t+1}, y_{r}^{t+1}\right)$ of Malmquist index is obtained by DEA model; then the Malmquist index from $t$ period to $t+1$ period of the $r$-th decision-making unit can be expressed as

$$
\begin{aligned}
\mathrm{TFP} & =\left[\frac{D^{t}\left(x_{r}^{t+1}, y_{r}^{t+1}\right)}{D^{t+1}\left(x_{r}^{t+1}, y_{r}^{t+1}\right)} \times \frac{D^{t}\left(x_{r}^{t}, y_{r}^{t}\right)}{D^{t+1}\left(x_{r}^{t}, y_{r}^{t}\right)}\right]^{1 / 2} \times \frac{D^{t+1}\left(x_{r}^{t+1}, y_{r}^{t+1}\right)}{D^{t}\left(x_{r}^{t}, y_{r}^{t}\right)} \\
& =\mathrm{TC} \times \mathrm{EC}=\mathrm{TC} \times \mathrm{PE} \times \mathrm{SE} .
\end{aligned}
$$

Malmquist index is the change degree of total factor productivity (TFP). When TFP $>1$, TFP shows an upward trend; TFP $=1$ indicates that TFP will not change with time. When TFP $<1$, TFP shows a downward trend. TFP can be decomposed into technical change (TC) and efficiency change (EC), and EC can be further decomposed into pure technical efficiency (PE) and scale efficiency (SE).

$\mathrm{TC}$ reflects the innovation level of technological innovation and management methods. When TC $>1$, it indicates technological progress; otherwise, technology will regress. EC measures whether there is a waste of input factors and whether the resource allocation is optimal. When EC $>1$, the technical efficiency is improved; otherwise, the technical efficiency is reduced. SE reflects whether the decision-making unit is in the optimal scale. When SE $>1$, it indicates that the evaluation object should expand the scale; otherwise, it should reduce the scale. PE reflects the effective utilization degree of the technology and management of the evaluation object. When $\mathrm{PE}>1$, it indicates that the pure technical efficiency is improved; otherwise, the pure technical efficiency is decreased.

2.3. $G M(1, N)$ Model. Although DEA-Malmquist method realizes the measurement and analysis of efficiency, it does not get the specific influencing factors of efficiency, so it is necessary to analyze the specific influencing factors of efficiency. $\operatorname{GM}(1, N)$ model is a differential equation prediction model with first-order $N$ variables, which reflects the influence of $N-1$ influencing factor variables on the first derivative of one system behavior variable. The characteristic sequence of system behavior can be expressed as

$$
X_{1}^{(0)}=\left(x_{1}^{(0)}(1), \ldots, x_{1}^{(0)}(i), \ldots, x_{1}^{(0)}(n)\right) .
$$

Influencing factor sequence $X_{i}^{\prime}(i=1,2, \ldots, m)$ can be expressed as 


$$
\begin{aligned}
X_{2}^{(0)} & =\left(x_{2}^{(0)}(1), \ldots, x_{2}^{(0)}(i), \ldots, x_{2}^{(0)}(n)\right), \\
X_{3}^{(0)} & =\left(x_{3}^{(0)}(1), \ldots, x_{3}^{(0)}(i), \ldots, x_{3}^{(0)}(n)\right), \\
\vdots & \\
X_{N}^{(0)} & =\left(x_{N}^{(0)}(1), \ldots, x_{N}^{(0)}(i), \ldots, x_{N}^{(0)}(n)\right) .
\end{aligned}
$$

Let $X_{j}(1)$ be the 1 -AGO sequence of $X_{j}(0)(j=1,2, \ldots, N)$ and let $Z^{(1)}$ be the nearest neighbor mean generating sequence of $X_{1}{ }^{(1)}$; then

$$
x_{1}^{(0)}(k)+a(z)_{1}^{(1)}(k)=\sum_{j=2}^{N} b_{j} x_{j}^{(1)}(k), \quad k=1,2, \ldots, n,
$$

TABLE 1: Evaluation index system of vegetable circulation efficiency in Henan Province.

\begin{tabular}{lc}
\hline Criterion layer & Index layer \\
\hline Input index & Labor input \\
Output index & Capital input \\
\hline
\end{tabular}

is called $\mathrm{GM}(1, \mathrm{~N})$ model.

When the amplitude of change of $X_{j}^{(1)}(j=1,2, \ldots, N)$ is very small, the approximate time response of $\operatorname{GM}(1, N)$ is as follows:

$$
\widehat{x}_{1}(k+1)=\frac{1}{\alpha} \sum_{j=2}^{N} b_{i}(x)_{i}^{(1)}(k+1)+\left[(x)_{1}^{(1)}(0)-\frac{1}{a} \sum_{j=2}^{N} b_{i}(x)_{i}^{(1)}(k+1)\right] e^{-a k}, k=1,2, \ldots, n
$$

where $x_{1}^{(1)}(0)$ is taken as $x_{1}{ }^{(0)}(1)$. follows:

The predicted values of system behavior variables are as

$$
\widehat{x}_{1}^{(0)}(k+1)=\widehat{x}_{1}^{(1)}(k+1)-\widehat{x}_{1}^{(1)}(k)
$$

\section{Empirical Analysis}

Based on the relevant research results at home and abroad, considering the validity and availability of sample data and the requirements of DEA model, this paper analyzes and evaluates the vegetable circulation efficiency of Henan Province from 2014 to 2019 . The sample data comes from Henan statistical yearbook, and the relevant data from 2014 to 2019 are selected for research. The number of employees in transportation, warehousing, wholesale, and retail industries has a missing value, which is supplemented by the average value of the years before and after the missing value.

\subsection{Evaluation Index of Vegetable Circulation Efficiency in} Henan Province. Input indicators are measured from two aspects: labor input $X_{1}$ (expressed by the total number of employees in transportation, as well as storage and wholesale and retail industries related to vegetable circulation) and capital input $X_{2}$ (expressed by the total fixed investment in transportation, as well as storage and wholesale and retail industries related to vegetable circulation). The output index is measured by the total amount of vegetable circulation $Y$, which is expressed by the total amount of vegetable consumption of urban residents. The evaluation index system of vegetable circulation efficiency is shown in Table 1.

\subsection{Factors Influencing Vegetable Circulation Efficiency in} Henan Province. In order to further investigate the specific influencing factors of vegetable circulation efficiency in Henan Province, according to the relevant theories of commodity circulation and referring to the relevant research results at home and abroad, the vegetable circulation efficiency is selected as the explained variable, and then the transportation infrastructure construction (expressed by highway mileage), labor quality (expressed by the number of college graduates), and the quality of labor force (expressed by the number of college graduates) are selected. Industrial structure (expressed by the proportion of the tertiary industry in GDP), consumption capacity (expressed by the total food consumption expenditure of urban residents), informatization level (expressed by the total telecommunications business), and government support (expressed by the general public budget expenditure of transportation) are used as explanatory variables to establish a grey $\operatorname{GM}(1, N)$ model and analyze the influencing factors. The influencing factors of vegetable circulation efficiency are shown in Table 2.

3.3. Static Analysis of DEA Model. Comprehensive efficiency is a comprehensive measure and evaluation of the resource allocation ability and utilization efficiency of decisionmaking units. Pure technical efficiency is the production efficiency influenced by management level and technical level, while scale efficiency is the production efficiency influenced by production scale. Deap 2.1 software is used to analyze the vegetable circulation efficiency of Henan Province in 2014 and 2019, and the comprehensive efficiency value, pure technical efficiency value, and scale efficiency value of vegetable circulation efficiency are obtained. The results are shown in Table 3.

(1) From the comprehensive efficiency index, the vegetable circulation efficiency of Henan province did not reach DEA efficiency in 2014 and 2019, and the comprehensive efficiency values were 0.789 and 0.772 , respectively. From the regional point of view, there are some differences in the circulation 
TABLe 2: Influencing factors of vegetable circulation efficiency in Henan Province.

\begin{tabular}{lc}
\hline Influence factors & Description \\
\hline Transportation infrastructure construction & Expressed by highway mileage \\
Quality of labor force & $\begin{array}{c}\text { Expressed by the number of college graduates } \\
\text { Industrial structure }\end{array}$ \\
Consumption power & Expressed by the proportion of the tertiary industry in GDP \\
Informatization level & Expressed by the total food consumption expenditure of urban residents \\
Government support & Expressed by the total amount of telecommunication services \\
\end{tabular}

TABle 3: Vegetable circulation efficiency of Henan Province in 2014 and 2019.

\begin{tabular}{|c|c|c|c|c|c|c|c|c|}
\hline \multirow[b]{2}{*}{ Prefecture } & \multicolumn{4}{|c|}{2014} & \multicolumn{4}{|c|}{2019} \\
\hline & $\begin{array}{l}\text { Synthetic } \\
\text { efficiency }\end{array}$ & $\begin{array}{l}\text { Technical } \\
\text { efficiency }\end{array}$ & $\begin{array}{c}\text { Scale } \\
\text { efficiency }\end{array}$ & $\begin{array}{c}\text { Returns to } \\
\text { scale }\end{array}$ & $\begin{array}{l}\text { Synthetic } \\
\text { efficiency }\end{array}$ & $\begin{array}{l}\text { Technical } \\
\text { efficiency }\end{array}$ & $\begin{array}{c}\text { Scale } \\
\text { efficiency }\end{array}$ & $\begin{array}{c}\text { Returns to } \\
\text { scale }\end{array}$ \\
\hline Zhengzhou & 0.708 & 1 & 0.708 & drs & 0.782 & 1 & 0.782 & drs \\
\hline Kaifeng & 0.660 & 0.702 & 0.940 & drs & 0.932 & 1 & 0.932 & irs \\
\hline Luoyang & 1 & 1 & 1 & - & 0.755 & 0.812 & 0.929 & drs \\
\hline Pingdingshan & 0.928 & 0.992 & 0.936 & drs & 1 & 1 & 1 & - \\
\hline Anyang & 0.820 & 0.903 & 0.908 & drs & 1 & 1 & 1 & - \\
\hline Hebi & 1 & 1 & 1 & - & 0.913 & 1 & 0.913 & irs \\
\hline Xinxiang & 0.901 & 1 & 0.901 & drs & 0.891 & 0.891 & 0.999 & irs \\
\hline Jiaozuo & 0.566 & 0.587 & 0.964 & drs & 0.703 & 0.721 & 0.975 & irs \\
\hline Puyang & 0.862 & 0.902 & 0.956 & drs & 0.574 & 0.591 & 0.971 & irs \\
\hline Xuchang & 0.529 & 0.578 & 0.916 & drs & 0.774 & 0.785 & 0.985 & irs \\
\hline Luohe & 0.908 & 0.942 & 0.964 & irs & 0.624 & 0.647 & 0.965 & irs \\
\hline Sanmenxia & 0.549 & 0.641 & 0.857 & irs & 0.855 & 0.888 & 0.963 & irs \\
\hline Nanyang & 0.952 & 1 & 0.952 & drs & 0.850 & 0.999 & 0.851 & drs \\
\hline Shangqiu & 0.598 & 0.606 & 0.986 & drs & 0.443 & 0.461 & 0.960 & irs \\
\hline Xinyang & 0.745 & 0.774 & 0.962 & drs & 0.628 & 0.631 & 0.995 & drs \\
\hline Zhoukou & 0.726 & 0.733 & 0.989 & drs & 0.825 & 0.963 & 0.857 & drs \\
\hline Zhumadian & 1 & 1 & 1 & - & 0.536 & 0.543 & 0.987 & irs \\
\hline Jiyuan & 0.754 & 1 & 0.754 & irs & 0.805 & 1 & 0.805 & irs \\
\hline $\begin{array}{l}\text { Evaluation } \\
\text { value }\end{array}$ & 0.789 & 0.853 & 0.927 & & 0.772 & 0.830 & 0.937 & \\
\hline
\end{tabular}

efficiency of different regions. Except for Luoyang, Hebi, Xinxiang, Puyang, Luohe, Nanyang, Shangqiu, Xinyang, and Zhumadian, the comprehensive efficiency of other regions is increasing. Pingdingshan and Anyang would reach the production frontier in 2019, which shows that the optimal allocation of resource input in these areas has been realized, the structure is reasonable, and the input-output has reached the optimal effect. Shangqiu, Zhumadian, and Puyang are in the last three places, and the comprehensive efficiency values are $0.443,0.536$, and 0.574 , respectively. The main reason is that the technical efficiency is too low. Therefore, these areas should pay attention to improving the management level and technical level.

(2) From the technical efficiency index, the technical efficiencies of vegetable circulation in Henan Province in 2014 and 2017 were 0.853 and 0.937 , respectively, which did not reach the production frontier, indicating that the management level and technical level are the main reasons restricting the improvement of vegetable circulation efficiency in Henan Province. In 2014 and 2017, Zhengzhou, $\mathrm{Hebi}$, and Jiyuan are the regions with effective technical efficiency, which indicates that these cities are more advanced in management and technology, and resources have been fully utilized. The scale efficiency value is the main reason for the low comprehensive efficiency of these cities. These areas should adjust the investment scale to improve the scale efficiency index.

(3) From the scale efficiency index, the scale efficiencies of vegetable circulation in Henan Province in 2014 and 2017 were 0.927 and 0.937 , respectively. The scale efficiencies of Zhengzhou, Nanyang, Zhoukou, and Jiyuan are at a low level, among which Zhengzhou, Nanyang, and Zhoukou are areas with increasing returns to scale. We should appropriately increase the input of labor, capital, and other factors and reasonably allocate the proportion to ensure the full use of resources. Jiyuan belongs to the area of diminishing returns to scale, so the direction of capital use should be adjusted.

3.4. Dynamic Analysis of Malmquist Index. Malmquist index can dynamically reflect the change trend of the overall efficiency of vegetable circulation in Henan Province. 
Table 4: Malmquist index of vegetable circulation in Henan Province from 2014 to 2019.

\begin{tabular}{lccccc}
\hline Year & Technical efficiency & Technical progress & Pure technical efficiency & Scale efficiency & Total factor productivity \\
\hline $2014-2015$ & 1.048 & 0.834 & 1.035 & 1.012 & 0.874 \\
$2015-2016$ & 0.940 & 1.113 & 0.947 & 0.993 & 0.978 \\
$2016-2017$ & 1.036 & 0.871 & 1.060 & 1.021 & 0.902 \\
$2017-2018$ & 0.987 & 0.944 & 0.967 & 1.009 & 0.932 \\
$2018-2019$ & 0.970 & 1.112 & 0.961 & 1.002 & 1.079 \\
Mean value & 0.995 & 0.968 & 0.993 & & 0.963 \\
\hline
\end{tabular}

Table 5: Malmquist index of vegetable circulation in Henan Province.

\begin{tabular}{lccccc}
\hline Prefecture & Technical efficiency & Technical progress & Pure technical efficiency & Scale efficiency & Total factor productivity \\
\hline Zhengzhou & 1.020 & 0.948 & 1.000 & 1.020 & 0.967 \\
Kaifeng & 1.071 & 1.044 & 1.073 & 0.998 & 0.985 \\
Luoyang & 0.945 & 0.944 & 0.959 & 1.013 & 0.893 \\
Pingdingshan & 1.015 & 0.962 & 1.002 & 1.020 & 0.976 \\
Anyang & 1.041 & 1.027 & 1.021 & 0.982 & 1.068 \\
Hebi & 0.982 & 0.963 & 1.000 & 1.021 & 0.945 \\
Xinxiang & 0.998 & 0.956 & 0.977 & 1.002 & 0.954 \\
Jiaozuo & 1.044 & 0.931 & 1.042 & 1.003 & 0.973 \\
Puyang & 0.922 & 0.944 & 0.919 & 1.015 & 0.871 \\
Xuchang & 1.079 & 0.933 & 1.063 & 1.000 & 1.006 \\
Luohe & 0.928 & 0.934 & 0.928 & 1.024 & 0.867 \\
Sanmenxia & 1.093 & 0.937 & 1.067 & 0.978 & 1.024 \\
Nanyang & 0.978 & 0.968 & 0.947 & 0.995 & 0.946 \\
Shangqiu & 0.942 & 1.029 & 0.960 & 1.007 & 0.969 \\
Xinyang & 0.966 & 0.981 & 1.056 & 0.972 & 0.948 \\
Zhoukou & 1.026 & 1.023 & 0.885 & 0.997 & 1.049 \\
Zhumadian & 0.883 & 0.992 & 1.000 & 1.013 & 0.875 \\
Jiyuan & 1.013 & 0.915 & 0.993 & 1.002 & 0.963 \\
Mean value & 0.995 & 0.968 & & & \\
\hline
\end{tabular}

Therefore, this paper uses DEAP 2.1 software to analyze and decompose the Malmquist index of 18 cities in Henan Province from 2014 to 2019. The specific results are shown in Tables 4 and 5 .

(1) Analysis of the overall efficiency changes. It can be seen from Table 4 that there are fluctuations in the efficiency indexes of Henan Province. The total factor productivity index from 2014 to 2015 is 0.874 , and the total factor productivity index from 2018 to 2019 is 1.079 , indicating that the vegetable circulation efficiency of Henan Province is on the rise year by year. From the decomposition results of Malmquist index, the technical efficiency index and technical progress index from 2014 to 2015 are 1.048 and 0.834 , respectively, and the technical efficiency index and technical progress index from 2018 to 2019 are 0.970 and 1.112, respectively, indicating that the technical efficiency index is in a downward trend, while the technical progress index is in an upward trend. It is shown that the main reason for the increase of vegetable circulation efficiency in Henan Province is the contribution of technological progress. The averages of pure technical efficiency index and scale efficiency index of vegetable circulation in Henan Province from 2014 to 2019 are 0.993 and 1.002 , respectively, indicating that the main reason for the decline of technical efficiency in Henan Province lies in the decline of pure technical efficiency year by year. Henan Province needs to improve the management level and optimize the allocation of resources to promote the improvement of vegetable circulation efficiency in Henan Province.

(2) Analysis of efficiency change in different regions. It can be seen from Table 5 that, during 2014-2019, except for Kaifeng, Anyang, Xuchang, Sanmenxia, and Zhoukou, the total factor productivity index of vegetable circulation in the other 13 cities is less than 1 , indicating that the vegetable circulation efficiency in most areas of Henan Province presents a downward trend. The decline of vegetable circulation efficiency in Zhengzhou, Pingdingshan, Shangqiu, Luoyang, Hebi, Xinxiang, Jiaozuo, Puyang, Luohe, Nanyang, Xinyang, Zhumadian, and Jiyuan is due to the joint effect of technological progress and technical efficiency.

3.5. Analysis of Influencing Factors of $G M(1, N)$ Model. This paper measures the efficiency of vegetable circulation in Henan Province by Malmquist index analysis method and decomposes the total factor productivity (TFP) index. The main problem of vegetable circulation in Henan Province is 
that the management level and technical level are weak, but we do not know the specific influencing factors of vegetable circulation efficiency in Henan Province and their influence degree and direction. It is necessary to further analyze the influencing factors of vegetable circulation efficiency.
Combined with the basic principle of $\operatorname{GM}(1, N)$ model, the grey system theory modeling software 7.0 is used to obtain the analysis model of influencing factors of vegetable circulation efficiency in Henan Province:

$$
\begin{aligned}
(x)_{1}^{(0)}(k)+0.8568(z)_{1}^{(1)}(k)= & -0.0828(x)_{2}^{(1)}(k)+0.0198(x)_{3}^{(1)}(k) \\
& +3.9755(x)_{4}^{(1)}(k)-0.0003(x)_{5}^{(1)}(k)-0.0001(x)_{6}^{(1)}(k)+0.0035(x)_{7}^{(1)}(k) .
\end{aligned}
$$

The analysis model of influencing factors of vegetable circulation efficiency in Henan Province shows that the coefficients of transportation infrastructure construction, consumption capacity, and informatization level are all negative, which indicates that these factors play a reverse role in hindering the improvement of vegetable circulation efficiency. The coefficients of labor quality, industrial structure, and government support are all positive, indicating that these factors play a positive role in promoting the circulation efficiency of vegetables. The main reasons are as follows: Henan is a large agricultural province with low urbanization rate, slow rural economic development, weak transportation infrastructure, and unsmooth transportation of agricultural products, which to a certain extent restricts the improvement of vegetable circulation efficiency in Henan Province, and the function coefficient reaches 0.0828 . The consumption ability of urban residents in Henan Province is relatively weak. For example, in the first half of 2019, the per capita consumption expenditure of 31 provinces in China ranked 25th with 7840 yuan. The consumption level of urban residents is low, which also affects the development of vegetable circulation industry in Henan Province to a certain extent, but the effect is relatively weak, and the effect coefficient is only 0.0003. Informatization is the driving force for the development of modern circulation industry, and the level of informatization also affects the improvement of vegetable circulation efficiency to a certain extent. For a long time, the development level of informatization in Henan Province is relatively backward, which hinders the improvement of vegetable circulation efficiency in Henan Province, but the effect is very weak, and the effect coefficient is only 0.0001 .

\section{Conclusion and Suggestion}

4.1. Conclusion. From 2014 to 2019, the vegetable circulation productivity of Henan Province was on the rise. During 2014-2015 and 2016-2017, the pure technical efficiency of vegetable circulation in Henan Province was relatively high, and the average value of pure technical efficiency during 2014-2019 was 0.993, which indicates that there are some innovations in vegetable circulation technology in Henan Province. The vegetable circulation in Henan Province has a higher scale efficiency value during 2014-2015 and 2017-2019, and the average scale efficiency during 2014-2019 was 1.002, which indicates that Henan Province has a good effect in industrial structure optimization and management level improvement. The technical efficiency of Henan Province during 2014-2015 and 2016-2017 was greater than 1, and the average technical efficiency during 2014-2019 was 0.995, which indicates that the vegetable circulation in Henan Province has high regulation and innovation ability. During 2015-2016 and 2018-2019, the vegetable circulation industry in Henan Province has a high technological progress index, which indicates that Henan Province has a high technological innovation ability.

From 2014 to 2019, the vegetable circulation productivity index in most areas of Henan Province was less than 1, which indicates that the vegetable circulation efficiency presents a downward trend, and the vegetable circulation efficiency in 10 areas presents a downward trend, which is the result of the synchronous decline of the technical progress index and the technical efficiency index. However, the pure technical efficiency index and scale efficiency index of 11 regions were greater than 1, which indicates that these regions have good effects in the optimization of industrial structure, the improvement of management level, and the innovation of circulation technology.

4.2. Suggestion. In terms of capital investment, Zhengzhou, Luoyang, Nanyang, Xinyang, and Zhoukou are in the stage of increasing returns to scale. Increasing the investment of capital elements appropriately in order to improve the efficiency of vegetable circulation is suggested. Excessive capital input may lead to waste of resources. Kaifeng, Hebi, Xinxiang, Jiaozuo, Puyang, Xuchang, Luohe, Sanmenxia, Shangqiu, Zhumadian, and Jiyuan are in the stage of diminishing returns to scale. It is suggested that capital input should be reduced to improve the efficiency of vegetable circulation.

Transportation Infrastructure Construction. The construction of transportation infrastructure plays an important role in promoting vegetable transportation. A perfect transportation network can speed up the circulation of vegetables and increase the circulation of vegetables. Henan Province should increase the investment and construction of vegetable circulation infrastructure, improve the transportation system, build efficient and convenient transportation infrastructure network, reduce the circulation cost, and improve the vegetable circulation speed. 
Consumption Ability. The consumption ability of residents is the basic power to improve the efficiency of vegetable circulation. The increase of disposable income of urban residents can increase their purchasing power, promote the scale of vegetable circulation, and improve the efficiency of vegetable circulation. Henan Province should formulate relevant policies to improve the wage level of enterprise employees and establish a normal wage growth mechanism. At the same time, the government should strengthen macro control, restrain the fluctuation of vegetable prices, stabilize the consumption expectations of urban residents, and relieve the worries of consumption.

The Level of Informatization. Informatization is the driving force and symbol of the development of modern circulation industry. The speed of information dissemination determines the circulation speed and quality of vegetables. To improve the circulation speed of vegetables in Henan Province, we need to speed up the construction of vegetable information service and improve the vegetable information service network. Henan Province should promote the opening and sharing of vegetable circulation information, build a public information platform for vegetable circulation, promote the effective connection between various links of vegetable circulation in Henan Province through platform services, promote the optimal allocation of resources, and improve the efficiency of vegetable circulation.

Labor Quality. High-quality vegetable circulation human capital can improve the quality and level of vegetable circulation service, reduce the cost of circulation management, and promote the improvement of circulation efficiency. Henan Province should pay attention to the introduction of vegetable circulation management personnel and technical personnel and, at the same time, strengthen the training of employees to improve their vocational skills.

Industrial Structure. Industrial structure is the proportion of output value of vegetable circulation related industries in GDP, which reflects the development of vegetable circulation industry in the region. Most of the vegetable circulation related industries belong to the tertiary industry, such as the developed wholesale and retail of agricultural products, which will create a good external environment for the development of vegetable circulation industry. Henan Province should vigorously develop the tertiary industry, promote the optimization of industrial structure, prosper the market economy, and promote the development of vegetable circulation industry.

The Degree of Government Support. The degree of government support for vegetable circulation is an important guarantee to improve the efficiency of vegetable circulation. Henan Province should pay attention to the planning of vegetable circulation industry, promote the rational distribution of vegetable wholesale market, and improve the financial and tax policies related to vegetable circulation, such as giving preferential policies in land use, tax, and loans.

\section{Data Availability}

The data used to support the findings of this study are available from the first author upon request.

\section{Conflicts of Interest}

The authors declare no conflicts of interest.

\section{Authors' Contributions}

Bingjun Li was responsible for proposing the overall idea and framework of the manuscript. Xueqiang Guo was responsible for data processing and writing of the first draft of the manuscript.

\section{Acknowledgments}

This work was supported by the Key Project of Soft Science Research in Henan Province (202400410051).

\section{References}

[1] X. H. Zhang, "Problems and countermeasures of vegetable market circulation in China," Journal of Changjiang Vegetables, vol. 11, pp. 55-56, 2006.

[2] H. C. Yuan and Y. H. Xin, "Problems and countermeasures of vegetable planting and circulation in China," Jiangsu Commercial Forum, vol. 7, pp. 13-14, 2011.

[3] S. L. Wang and M. J. Chen, "Current situation and development countermeasures of vegetable circulation in China," Chinese Vegetables, vol. 7, pp. 1-5, 2013.

[4] S. Wu and Y. Y. Mu, "Analysis of vegetable circulation and its influencing factors in China based on temporal and spatial characteristics," Business Economics and Administration, vol. 292, no. 2, pp. 18-25, 2016.

[5] M. Kuang, P. Dong, X. F. Luo, and S. R. Li, "Difficulties and countermeasures of vegetable production and market circulation in Chongqing," Chinese Vegetables, vol. 6, pp. 9-13, 2016.

[6] X. Shang and Z. Huang, "Cai Wenji, poet, Eastern Han dynasty," Notable Women of China, vol. 3, pp. 155-157, 2016.

[7] C. Shen, L. Xiong, S. Q. Han, J. J. Ma, and J. Z. Ma, "Analysis on the production and circulation situation of fruits and vegetables in China," Chinese Vegetables, vol. 9, pp. 7-11, 2017.

[8] C. Shen and Y. Y. Mu, "Analysis on spatial and temporal characteristics of Beijing vegetable market circulation based on production and marketing correlation-taking Chinese cabbage, cucumber and tomato as examples," Chinese Vegetables, vol. 11, pp. 10-15, 2019.

[9] Y. H. Zhou and L. X. Lu, "Study on the efficiency of fresh vegetable supply chain-taking Nanjing as an example," Jiangsu Agricultural Sciences, vol. 1, pp. 69-72, 2008.

[10] W. Su, "Thoughts on improving the circulation efficiency of agricultural products-based on the perspective of the construction of agricultural products wholesale market," Commercial Age, vol. 13, pp. 30-31, 2012.

[11] W. J. He and H. Wu, "Analysis of vegetable circulation efficiency in Wuhan based on cost index," Journal of Wuhan Metallurgical Manager's Institute, vol. 23, no. 2, pp. 23-26, 2013. 
[12] N. Guo, "The efficiency of fresh vegetable circulation channel with supermarket as retail terminal," China Business and Market, vol. 1, pp. 17-21, 2013.

[13] P. Jiang, L. Hao, and A. S. Ren, "Analysis and countermeasures of main influencing factors of vegetable circulation efficiency in Beijing based on analytic hierarchy process," Jiangsu Agricultural Sciences, vol. 42, no. 2, pp. 402-404, 2014.

[14] P. Jiang, Study on the Circulation Efficiency of Vegetables in Beijing Suburbs, Chinese Academy of Agricultural Sciences, Beijing, China, 2014.

[15] W. L. Zhang, "Analysis and discussion on vegetable circulation efficiency-based on the perspective of vertical production and marketing links and horizontal circulation mode," Review of Economic Research, vol. 62, pp. 28-39, 2014.

[16] K. Kim and D. An, "Nonparametric evaluation of economies of scope in the context of technical efficiency: the case of rice and vegetable farms in Korea," Asian Economic Journal, vol. 29, no. 3, pp. 285-301, 2015.

[17] R. B. Shrestha, W. C. Huang, S. Gautam, and T. G. Johnson, "Efficiency of small scale vegetable farms: policy implications for the rural poverty reduction in Nepal," Agricultural Economics-zemedelska Ekonomika, vol. 62, no. 4, pp. 181-195, 2016.

[18] Y.Shan, Evaluation and Optimization of Vegetable Circulation Efficiency in Harbin, Northeast Agricultural University, Harbin, China, 2016.

[19] H. Peng and X. Y. Nan, "A comparative study on the differences of vegetable circulation efficiency between eastern and Western China," Journal of Huazhong Agricultural University (Social Science Edition), vol. 3, pp. 17-24, 2016.

[20] Y. Y. Zheng, "Measurement and improvement of fresh vegetable circulation efficiency from the perspective of industrial chain," Agricultural Economy, vol. 11, pp. 139-140, 2017.

[21] L. Li and Y. Y. Mu, "Comparison of vegetable circulation efficiency in different channels under the wholesale market leading mode-based on DEA Tobit model from the perspective of micro farmers," China Business and Market, vol. 31, no. 4, pp. 69-76, 2017.

[22] A. Akamin, J.-C. Bidogeza, J. R. Minkoua, and V. Afari-Sefa, "Efficiency and productivity analysis of vegetable farming within root and tuber-based systems in the humid tropics of Cameroon," Journal of Integrative Agriculture, vol. 16, no. 8, pp. 1865-1873, 2017.

[23] A. R. Anik and M. A. Salam, "Assessing and explaining vegetable growers' efficiency in the south-eastern hilly districts of Bangladesh," Journal of the Asia Pacific Economy, vol. 22, no. 4, pp. 680-695, 2017.

[24] R. Ye, An Empirical Study on the Circulation Efficiency and Decision Making Behavior of Vegetable Growers-A Survey of 148 Leafy Vegetables Farmers in Nanchang Suburb, Jiangxi Agricultural University, Nanchang, China, 2018.

[25] T. Bournaris, G. Vlontzos, and C. Moulogianni, "Efficiency of vegetables produced in glasshouses: the impact of data envelopment analysis (DEA) in land management decision making," Land, vol. 8, no. 1, p. 17, 2019.

[26] S. Nedumaran, A. Selvaraj, R. Nandi, B. Suchiradipta, P. Jyosthnaa, and D. Bose, "Digital integration to enhance market efficiency and inclusion of smallholder farmers: a proposed model for fresh fruit and vegetable supply chain," The International Food and Agribusiness Management Review, vol. 23, no. 3, pp. 319-337, 2020.

[27] X. Ma and Z. B. Liu, "Predicting the oil field production using the novel discrete GM $(1, \mathrm{~N})$ model," Journal of Grey System, vol. 27, no. 4, pp. 63-73, 2015.
[28] H. Jiang, Y. C. Hu, J. Y. Lin, and P. Jiang, “Analyzing China’s OFDI using a novel multivariate grey prediction model with Fourier series," International Journal of Intelligent Computing and Cybernetics, vol. 12, no. 3, 2019.

[29] X. Xiong, H. Guo, and X. Hu, "The housing demand analysis and prediction of the real estate based on the AWGM $(1, N)$ model," Grey Systems: Theory and Application, vol. 11, no. 2, 2020.

[30] W. M. Yang and B. J. Li, "Prediction of grain supply and demand structural balance in China based on grey models," Grey Systems: Theory and Application, vol. 11, no. 2, 2020. 